\title{
Temporal effects in binocular vision
}

T. G. R. Hower and L. J. Haley CORNELL UNIVERSITY

\begin{abstract}
Abstraet
The temporal parameters of the rivalry process are determined and the effects on them of stimulus variables are determined. No stimulus effect is found. It is concluded that rivalry is determined by structural properties of the organism.
\end{abstract}

\section{Problem}

Two major hypotheses concerning binocular rivalry have been put forward, that rivalry is a function of structural characteristics of the rivalrous stimulation (Breese, 1909) and that rivalry is a function of structural characteristics of the organism (Ogle, 1962). Evidence has recently been presented that rivalry as a process develops over time (Crovitz \& Lipscomb, 1963), Unfortunately the authors chose to work with colored fields. There is reason to believe that form and color are mediated by different rivalry mechanisms (Creed, 1935). However, if rivalry does develop in time, the parameters of the process should permit estimation of the relative effects of external and internal determinants of dominance. The problem, then, is to ascertain the parameters of rivalry as a process in time.

\section{Method}

Ten volunteers from an introductory psychology class served as Ss. The stimuli used were digit pairs, drawn in white on $7 \times 4$ in black cards. Digits were placed 1 in on each side of the center of the card. Two digit sizes, 1 in and $.5 \mathrm{in}$, were made. Card luminance was $1 \mathrm{ft}$ lambert. Two luminances, $15 \mathrm{ft}$ lamberts and $5 \mathrm{ft} \mathrm{lam-}$ berts were used, in conjunction with the 1 in digits.

Stimuli were presented in a Scientific Prototypes stereoscopic tachistoscope model GA. Ten presentation durations were used, 10-100 $\mathrm{msec}$, in $10 \mathrm{msec}$. steps. Each rivalrous presentation was preceded by a 2000 msec. adapting field, luminance $15 \mathrm{ft}$ lamberts.

Thirty presentations were given at each duration, (a) 10 with 1 in digits at $15 \mathrm{ft}$ lamberts to each eye, (b) 10 with .5 in digits to the non-dominant eye and 1 in digits to the dominant eye, both at $15 \mathrm{ft}$ lamberts, and (c) 10 with 1 in digits to both eyes, with dominant eye digit luminance $5 \mathrm{ft}$ lamberts, non-dominant eye digit luminance $15 \mathrm{ft}$ lamberts.

Only completely rivalrous digit pairs were presented. Duration and manner of presentation were completely randomized. Digits were presented in registry.

Dominance was determined by finding Ss' .5 threshold for recognition of a digit pair, for each eye. Four ascending and four descending series were used. Thresholds ranged from $38 \mathrm{msec}$. to $74 \mathrm{msec}$.

5s were asked to report all of the digits they could see.

\section{Results}

Only two kinds of report were obtained in this experiment. Ss either reported digits to the nasal hemiretinae, or they reported the digits coming to the dominant eye. Originally, probabilities of each kind of report for the equivalent stimuli condition were plotted against presentation duration. Since the resulting dot matrix did not seem very meaningful, a new time scale was constructed by dividing real time by each S's digit recognition threshold for the dominant eye. The resulting distribution was fitted by a normal ogive, giving chi square $=4.79(p>.9)$ and chi square $=5.01(p>.9)$. Distributions are shown in Fig. 1.

One other point should be noted. No S was able to give both kinds of report to a single presentation. Only two

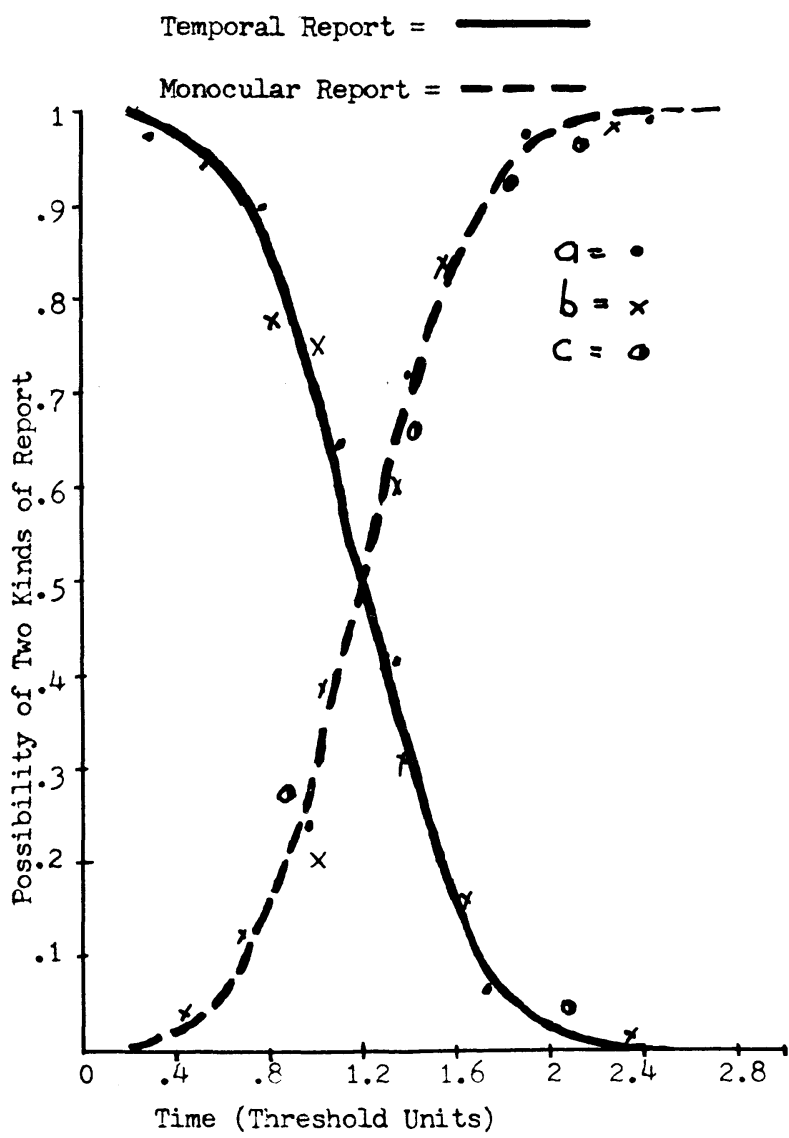

Fig. 1. Probabilities of two kinds of report at durations 10-100 msec. (plotted against time in dominant eye threshold units.) 


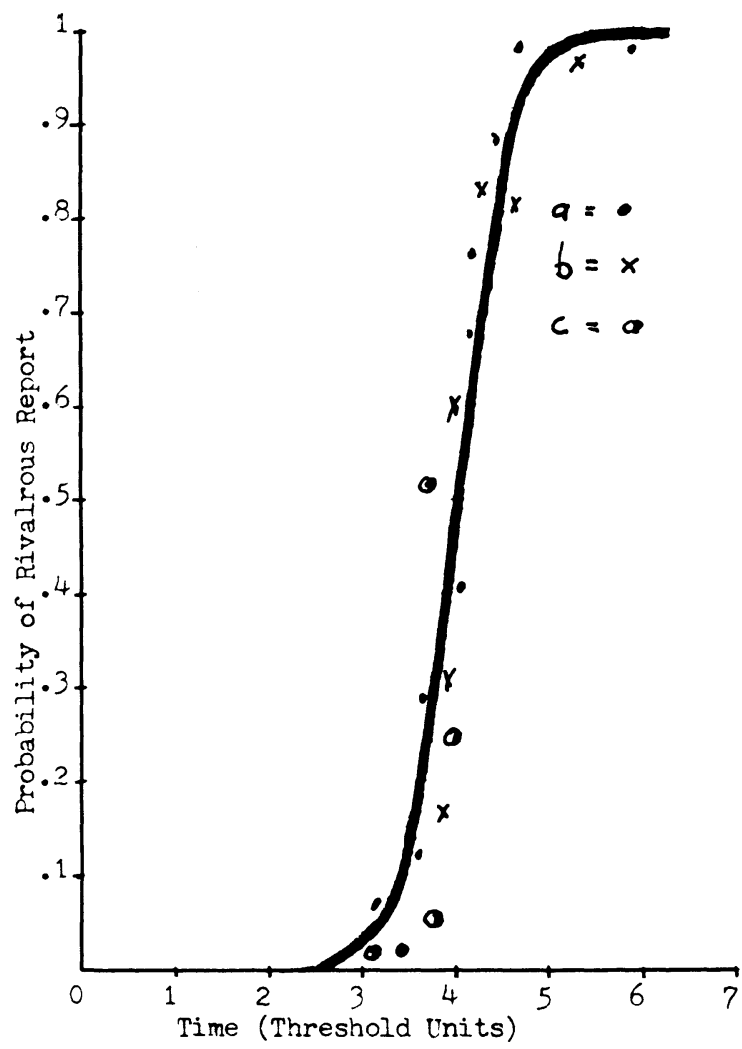

Fig. 2. Probabilities of two kinds of report at durations 150-650 msec. (plotted against time in non-dominant eye threshold units.)

digits were ever seen. The difference between dominant eye recognition thresholds with and without rivalrous input was not statistically significant. However, the correlation between relative efficiency of the nondominant eye and the degree of interference gave tau= $.8(\mathrm{p}<.05)$.

Since rivalry did not in fact occur in the first experiment, 10 further Ss were run with presentation durations of $150,250,350,450,550$ and $650 \mathrm{msec}$. Everything else was as in the previous experiment.
A new time scale was constructed as before, using non-dominant eye threshold (47-108 msec.) as a unit. Two major classes of report occurred, rivalry, "7 on 4, " and binocular, all four digits seen in LLRR or LRLR order. The resulting distributions are shown in Fig. 2. The best-fitting ogive gave chi-square of 3.7, 5.9 and 4.2 ( $p>.8$ for all three) for rivalrous report. Occasionally both reports were given to the same presentation.

Alpern (1962) gives $200 \mathrm{msec}$. as the completion time for a divergent movement. The time to $p=.5$ for rivalry was subtracted from the time to $\mathrm{p}=.5$ for binocular report giving as mean value $191.7 \quad(t=1.08 ; \mathrm{df}=9$; $\mathrm{p}>.2)$.

\section{Diseussion}

From the above it would seem that rivalry is an organismic rather than a stimulus determined process. As a process it goes through four phases corresponding to read in from the nasal hemiretinae, read in from the dominant eye, rivalry, and binocular vision. Any explanation of suppression (phase 2) based on muscular responses must be rejected, since for all Ss the process was complete in less than $100 \mathrm{msec}$. The nature of phase 3 , rivalry, precludes any eye movement, save an accommodative change. This seems unlikely in view of the long latency of accommodation (Alpern, 1962). We may tentatively conclude that phase 3 serves as the stimulus for divergent eye movements, producing phase 4 . The masking relation holding between phase 2 and phase 1 , implicates storage and erasure mechanisms.

\section{References}

ALPERN, M. Eye movement. In H. Davson (Ed.), The Eye, vol. 3. London: Academic Press, 1962. Pp. 3-187.

BREESE, R. Binocular rivalry. Psychol. Rev., 1909, 11, $1-28$.

CREED, R. S. Some observations on rivalry. J. Physiol., 1935, 84, 381-391.

CROVITZ, H. F., \& LIPSCOMB, D. B. Dominance of the temporal visual fields at short durations of stimulation. Amer. J. Psychol., 1963, 76, 631-637.

OGLE, K. N. The visual space sense. In H. Dawson (Ed.), The Eye, vol. 4. London: Academic Press, 1962. Pp. 11-18. 